EXTENDED REPORT

\title{
The economic burden associated with osteoarthritis, rheumatoid arthritis, and hypertension: a comparative study
}

\author{
A Maetzel, L C Li, J Pencharz, G Tomlinson, C Bombardier, the Community Hypertension and \\ Arthritis Project Study Team
}

Ann Rheum Dis 2004;63:395-401. doi: 10.1136/ard.2003.006031

See end of article for authors' affiliations

Correspondence to:

Dr A Maetzel, University

Health Network, 200

Elizabeth Street EN 6-232

A, Toronto, Ontario M5G

2C4, Canada; maetzel@

uhnres.utoronto.ca

Accepted 4 June 2003

\begin{abstract}
Objective: To compare the economic burden to society incurred by patients with RA, OA, or high blood pressure (HBP) in Ontario, Canada.

Methods: Consecutive subjects recruited by 52 rheumatologists (RA) and 76 family physicians (OA and HBP) were interviewed at baseline and 3 months. Information was collected on demographics, health status, and any comorbidities. A detailed, open ended resource utilisation questionnaire inquired about the use of medical and non-medical resources and patient and care giver losses of time and related expenses. Annual costs were derived as recommended by national costing guidelines and converted to American dollars (year 2000). Statistical comparisons were made using ordinary least squares regression on raw and log transformed costs, and generalised linear modelling with adjustment for age, sex, educational attainment, and presence of comorbidities.

Results: Baseline and 3 month interviews were completed by $253 / 292$ (86.6\%) patients with RA and 473 / $585(80.9 \%)$ patients with OA and/or HBP. Baseline and total annual disease costs for RA $(n=253)$, OA and $\operatorname{HBP}(n=191), O A(n=140)$, and $\operatorname{HBP}(n=142)$, respectively, were $\$ 9300, \$ 4900, \$ 5700$, and US $\$ 3900$. Indirect costs related to RA were up to five times higher than indirect costs incurred by patients with $\mathrm{OA}$ or $\mathrm{HBP}$, or both. The presence of comorbidities was associated with disease costs for all diagnoses, cancelling out potential effects of age or sex.

Conclusion: The economic burden incurred by RA significantly exceeds that related to OA and HBP, while differences between patients with a diagnosis of OA without HBP or a diagnosis of HBP alone were nonsignificant, largely owing to the influence of comorbidities.
\end{abstract}

$\mathrm{T}$ 1997 National Health Interview Survey estimated that the prevalence of self reported arthritic disorders among non-institutionalised people in the United States was $16.1 \%$, with one in six $(2.9 \%$ overall $)$ reporting that arthritis limited their activity. ${ }^{1}$ Projections from the same survey indicated that the number of people with self reported arthritic disorders was likely to rise by 750000 a year in the $1990 s^{2}$ Such figures suggest that in future it will be necessary to devote increasing resources to improving the quality of life of arthritic patients by joint replacement surgery, pharmaceutical treatment, and homecare services.

Arthritic disorders pose a challenge to anyone concerned about healthcare costs, and their escalation leads to growing demands for more money to be devoted to arthritis research and caring. Cost of illness (COI) estimates for arthritic conditions are considerable when all levels of the healthcare system are taken into account. For example, in Canada, the total cost of arthritis and rheumatism in 1994 was broadly estimated to be between \$C4.3 and \$C7.3 billion. ${ }^{3}$ Estimates of medical expenses (which exclude the cost of time lost from paid or unpaid work) in the same year varied between \$C1.7 and \$C2.5 billion dollars. The latter (often referred to as direct costs) amounted to $2.9 \%$ of the 1994 total health expenditure in Canada of \$C72.5 billion, or $9.7 \%$ of the nation's gross domestic product (GDP).

COI studies are often undertaken to raise awareness among decision makers and the public about the economic burden of a disease, but their role in policy making remains unclear. Two systematic reviews concluded that the results of COI studies are not sufficiently reliable to inform policy making, citing three main reasons ${ }^{45}:(a)$ total cost estimates for a specific disorder can vary up to 40 -fold; $(b)$ indirect costs are generally overestimated (otherwise it is hard to explain how a few diseases can account for major reductions in a country's GDP); and (c) the costs associated with a limited list of diseases can easily exceed total medical care expenditure. If the results of COI studies are to be more useful in the future, it is recommended that the investigators should $(a)$ estimate indirect costs more conservatively; $(b)$ estimate incidence based costs; (c) if possible, analyse cost trends in order to gain more insight into the dynamic processes involved; (d) directly incorporate COI results in economic evaluations; and (e) perform one general COI study instead of several individual ones. ${ }^{5}$

The present investigation is a comparative COI study in patients with three disorders: high blood pressure (HBP), osteoarthritis (OA), and rheumatoid arthritis (RA). HBP was selected for comparison because it is very common in Western societies. ${ }^{6}$ The objectives are to $(a)$ measure the direct and indirect costs of illness associated with each disorder; $(b)$ determine the relative contribution of diagnosis to the direct and indirect costs; and $(c)$ estimate the costs attributable to other factors, such as age, education, sex, and the number of active comorbidities.

\section{METHODS}

Subject recruitment

Subjects were recruited from the practices of family physicians (OA and HBP) and rheumatologists (RA) in Ontario, Canada, between May 1999 and May 2000. A

Abbreviations: $\mathrm{COI}$, cost of illness; GDP, gross domestic product; GLM, generalised linear modelling; HBP, high blood pressure; OA, osteoarthritis; OLS, ordinary least squares; RA, rheumatoid arthritis 
random sample of 1936 of 3446 Ontario family physicians, members of the Canadian College of Family Physicians, was contacted in five separate mailings. Seventy six agreed to participate and enrolled seven consecutive patients eachfive with OA (with or without HBP) and two with HBP only. There were no statistically significant differences in sex, time since year of graduation, and age between the participating and non-participating family physicians. All rheumatologists registered in the province in $1999(n=135)$ were approached to recruit patients with RA, 52 participated and enrolled at least five consecutive subjects each. Responding rheumatologists did not differ in time since graduation, sex, and regional location of practice from non-respondents; 16 worked in an academic setting and the remaining 36 in the community.

Patients with OA and/or HBP were required to have been diagnosed by a physician and to be more than 55 years old. Patients with RA had to satisfy the 1987 American College of Rheumatology (ACR) diagnostic criteria ${ }^{7}$ and be aged at least 18 years. All participants had to be able to communicate in English and were required to provide written consent.

\section{Data collection}

Patients completed two telephone surveys, one at baseline and one 3 months later. The first included questions about the respondent's demographic characteristics, such as his or her marital status and educational attainment. Subjects were also asked whether they had any of 23 specific comorbidities and, if so, whether they had been treated for them in the previous year. Disease-specific and generic health related quality of life were assessed at both interviews using the SF36 (Short Form-36, version 1) questionnaire, a measure of general health, and physical and emotional wellbeing, ${ }^{8}$ and the Health Assessment Questionnaire. ${ }^{9}{ }^{10}$. Physician's global assessment of the patient's disease status was assessed on a five point Likert scale ( 1 , very poor; 5 , very well).

At the baseline and follow up interview, data on the use of all healthcare resources, not just disease related, over the previous 3 months were captured by a health resource utilisation questionnaire covering the following items:

- All consultations with health professionals, including the type of professional, the number of visits, the most important treatment prescribed, and the most important test or procedure performed.

- All visits, admissions, or procedures performed in a hospital, including the type of hospital department, the reason for the visit, the length of stay, and the most important test or procedure carried out.

- The numbers and types of tests performed independently of a visit to a health professional-for example, blood tests.

- All drugs taken (both prescribed and over the counter), including brand or generic names, the reasons/indications for use, the dosage, and the frequency and duration of administration.

- All adaptive aids, devices, and assistive household equipment purchased, including a description of the item, and details of any reimbursement and of any costs incurred by the patient.

- All community services or resources used (for example, home care, transportation services for people with disability such as WheelTrans, and food delivery services such as Meals On Wheels), including the type of service, the frequency of use, and the monthly cost borne by the patient.

- Any time lost from paid employment incurred by the patient or his/her main care giver as a result of the former's health problems.
- The amount of time for which the patient had difficulty working because of his or her health problems, and the percentage reduction in maximum working capacity.

- The amount of time for which the patient was unable to do chores around the house or similar activities because of health problems.

- Any paid help received by the patient because of a limited ability to do household chores (the time for which help was needed, or its cost).

- Any unpaid help the patient received because of a limited ability to do household chores (the time for which help was needed).

\section{Cost assignment}

All costs were assigned according to methods endorsed by the Canadian Coordinating Office for Health Technology Assessment. ${ }^{11}$ Medical expenses and indirect costs were multiplied by the American Canadian purchasing power parity for medical and health care, which was $\$ 1.23$ for each $\$ C 1.00$ in 1998. Indirect costs were multiplied by a factor of 0.84 , the purchasing power parity based on the GDP. ${ }^{12}$

\section{Direct costs}

Costs of visits to health professionals, of procedures performed, and of investigative tests undertaken were obtained from the Ontario Schedule of Benefits, l April 1999 version. $^{13}$ The costs of consultations with health professionals not covered under the Ontario Health Insurance Plan, such as chiropractors and massage therapists, were obtained from the relevant professional bodies. For non-regulated health professionals, an average billing rate was calculated on the basis of information provided by at least five practices in the Greater Toronto area.

The first step in calculating the cost of hospitalisation, including overnight stays, was to classify patients into case mix groups using a coding algorithm published by the Canadian Institute for Health Information. ${ }^{14}$ The resource intensity weight of each group was then determined by referring to a document provided by the Ontario Joint Policy and Planning Committee. ${ }^{15}$ Finally, the 1998 cost per weighted case for hospital stays in Ontario was multiplied by the resource intensity weight to give an estimate of the costs per patient of overnight hospital stays. Costs of ambulatory hospital clinic visits were assigned according to information in the 1999 Alberta Ambulatory Care Costing Survey. ${ }^{16}$ Each visit was given one of 391 codes and the appropriate cost was applied.

Costs of drugs were calculated on the basis of wholesale prices listed in the catalogue of a large Ontario based pharmaceutical supplier (Kohl and Frisch Ltd, September 1999). Prescription drugs were subject to a $10 \%$ pharmacy dispensing fee, and a prescription fee of \$C6.47. A 40\% profit mark-up was added to the price of over the counter agents. Costs per unit were calculated by dividing the cost per package by the number of units it contained. The overall cost of each drug per patient was calculated by multiplying the unit cost by the number of administrations.

Purchase prices of adaptive aids and devices were obtained from suppliers in the Greater Toronto area, including Shoppers Home Health Care (Doncaster), Therapists' Choice, and Therapy Supply. The cost of equipment partially funded by the provincial Assistive Device Program was obtained from the 1999 Wheelchair, Positioning and Ambulation Aids Manual. For services provided by the Community Care Access Centre, such as nursing, treatment, and home making services, the unit cost for each OA/HBP/RA case (based on the ICD-9CM code) was applied using a costing template provided by the Toronto Community Care 
Access Centre in February 2000. Costs related to other community services or resources used by patients, including transportation services, such as WheelTrans, and food delivery services, such as "Meals On Wheels", were determined by eliciting an average cost from the organisation concerned.

\section{Indirect costs}

Time lost from paid work by patients or their carers/ supporters was initially recorded in days or hours. Days were then converted to hours using Statistics Canada data (year 1998; http://www.statcan.ca) showing that an average working day of paid employment is 8.0 hours long. To calculate income lost because of absence from work or difficulty with paid employment, the average provincial hourly wage of someone matched for age and sex with the patient or carer was determined from data at the Institute of Health Economics (1997-98). ${ }^{11}$ This figure was then multiplied by the number of hours of work reportedly lost. Costs for the time a patient had difficulty working in a paid job were added, after adjustment for the estimated degree of reduction in his or her work capacity.

Time costs incurred through a patient's inability to do chores were obtained in two ways. Firstly, by multiplying the number of hours lost by a professional homemaker's hourly wage of $\$ 10$. When a patient reported time lost in days, each day was reckoned to represent 3.6 hours (Statistics Canada, 1998; http://www.statcan.ca). Secondly, the costs of paid and unpaid help received by patients for household chores were calculated by adding the amount paid by patients to an amount based on the time care givers spent providing unpaid help. The latter was determined by multiplying the time reported by patients by the hourly wage of a professional homemaker matched for age and sex. Results of the two methods were compared, and the higher value was selected to avoid double counting and to represent the total monetary cost of the patient's inability to do chores during the 6 month period covered by both study interviews.

\section{Analysis}

Baseline and 3 month data for participants who completed the protocol were analysed, and the average total 6 month cost per patient was calculated for each of the following health related resource use categories:

- Visits to health professionals

- Hospitalisations

- Tests and investigations

- Drugs

- Total direct costs, including costs pertaining to health professional visits, hospitalisation, laboratory tests, drugs, community services such as home care, and purchases of adaptive devices

- Total indirect costs, including relevant time costs incurred by patients and care givers, and time costs due to the patient's inability to perform household chores.

The following variables were tested in multivariable statistical comparisons of total, direct, and indirect costs: (a) diagnosis (HBP, OA, or RA); (b) educational attainment (coded as: 1, less than high school; 2, high school; 3 , college or university); (c) number of comorbidities treated in the preceding year, maximum 23; (d) sex; (e) age.

A generalised linear modelling (GLM) approach with a logarithmic link function was used to analyse datasets without zero dollar cost estimates (total costs and direct costs). ${ }^{17}$ Simulation studies have shown that ordinary least squares (OLS) regression of log transformed costs may be the preferred option, particularly in the presence of heavily skewed residuals. A disadvantage of OLS is the need to retransform predicted log transformed costs back to the original scale in order to calculate predicted costs and compare them with the observed cost estimates. However, this can be overcome by manipulating the log scale residuals. ${ }^{18} 19$ Both GLM based and OLS based comparisons were performed and the difference between predicted costs and observed costs was calculated for each.

Datasets with zero dollar cost estimates (indirect costs) were analysed using a proportional odds model owing to the potential for clumping. ${ }^{20}$ Five cost categories were constructed, one for zero costs and four more corresponding to quartiles of the non-zero costs. The proportional odds assumption was checked with the score test. In a second approach, a logistic regression was fitted with the binary outcome of zero or non-zero cost estimates and an OLS model was then fitted to the remaining non-zero, log transformed costs. $^{20}$

\section{RESULTS}

\section{Recruitment}

A total of 585 patients with OA or HBP were recruited, 70 did not meet eligibility criteria, 15 declined to participate, and seven could not be contacted, leaving 493. A further 20 dropped out (OA and HBP 7, OA 8, HBP 5 ) to give a final total of 473 participants, of whom 331 had OA (191 OA and HBP, 140 with OA alone) and 142 had HBP only. Patients with RA were recruited between October 1999 and May 2000. Of 292 volunteers, 20 were ineligible, could not be contacted or refused, and 19 dropped out after baseline for a final total of 253 (fig 1).

\section{Demographic and baseline characteristics}

As expected, patients with RA were generally younger than the groups with OA and HBP, with 109/253 (43.1\%) patients below the age of 55. Patients with RA also included a higher proportion of women, and were more likely to be in full time employment (table 1). However, the proportion of employed among the 144 patients with RA over age 55 was $12.5 \%$, similar to the employment rate observed among patients with HBP. Patients with RA tended to be more disabled and scored less well on the global health measure. They had fewer comorbidities than patients with OA with or without HBP, but not fewer comorbidities than patients with HBP. Among the 331 patients with OA, 185 had knee OA, 99 hip OA, 99 hand OA, and $176 \mathrm{OA}$ in the spine; many patients had more than one part affected by OA.

\section{Health resource use}

A large majority of patients with RA (94.5\%) had at least one investigative test in the 6 month period, compared with $77.0 \%$ of those in the OA and HBP group, $82.9 \%$ with OA alone, and $73.2 \%$ with HBP alone (table 2 ). The need for inpatient hospitalisation was low in all four groups, as was the use of community services, including home care. Almost $20 \%$ of patients with RA had purchased adaptive aids and devices in the previous 6 months, compared with $6.8 \%$ of those with OA and HBP, $7.9 \%$ of those with OA alone, and one patient $(0.7 \%)$ with HBP.

Productive time spent in the household and workplace was lower among patients with RA than in the OA or HBP groups. More than 53\% of patients with RA reported being unable to perform household chores, and even more $(60 \%)$ said they received unpaid help. Although more patients with RA reported taking time off from paid work because of their health, they were also more likely to be part of the active workforce. 


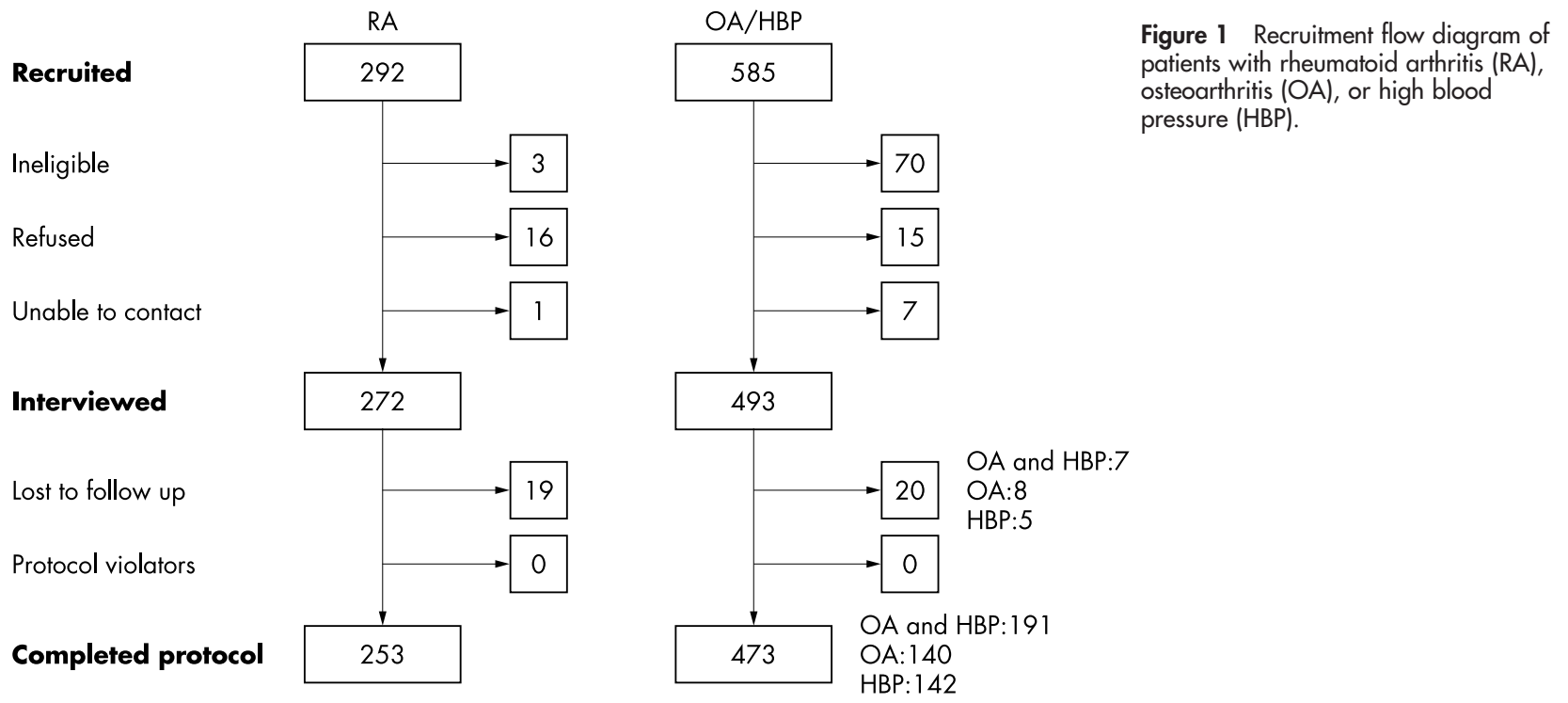

\section{Cost of illness}

Total 6 month costs related to RA were \$4674, compared with $\$ 2456$ for OA and HBP, \$2856 for OA, and \$1963 for HBP (table 3). Direct costs accounted for just over $80 \%$ of the total among patients with OA and HBP, but only $55.1 \%$ in RA. Almost half of all direct costs in all patient groups were attributable to drug costs. Arthritis prescription drugs accounted for a large proportion of drug costs in patients with RA, as did visits to specialists (which, in turn, comprised a larger proportion of health professional visits). Similarly, expenditure on tests was higher in RA. The indirect cost of RA was estimated to be $\$ 2098$ per 6 month periodconsiderably higher than that of OA with or without HBP, or HBP (table 3). HBP was also diagnosed among 72 (28.5\%) patients with RA; total costs were $\$ 5105$ and $\$ 4540$ per 6 month period for those with and without HBP.

Tabulation of costs for each diagnosis and some of the variables selected for use in the regression model (except global health status) revealed a linear trend toward increased costs with worsening global health status, and (though less linear) with increasing numbers of comorbidities (table 4). No other such trends were seen.

\section{Role of diagnosis and other factors}

The GLM approach was used first to test how strong an influence important covariables had on total costs. However, use of this model resulted in a less than perfect fit, with residuals heavily skewed to the right (kurtosis of 13.5). A far better fit was achieved with OLS regression on the log transformed total costs, which gave residuals that were approximately normally distributed and centred on zero with a kurtosis of 0 . Despite differences in model fit, the statistical significance of the findings of both tests was similar (table 5). A diagnosis of RA and the number of comorbidities, including that of HBP for patients with RA, significantly influenced total costs $(p<0.0001)$, mostly by influencing direct costs. A diagnosis of OA with HBP also had a significant effect on the direct costs when compared with HBP alone (table 5), whereas no significant differences were observed between OA alone versus HBP alone. Results were no different when the analysis was limited to patients with RA who were over the age of 55. A diagnosis of OA overall, with or without HBP, was not significantly associated with higher direct healthcare costs after adjustment for the number of comorbid disorders (data not shown in the tables). The presence of comorbidities was a powerful predictor of costs. Together with the other co variables, it explained $31 \%$ of the variance in $\log$ transformed total costs, and $24 \%$ of that in log transformed direct costs.

When indirect costs were analysed with OLS on log transformed non-zero costs, excluding all patients with zero costs, no obviously significant contributor was identified. The picture was not much clearer when patients with zero costs were included by applying a proportional odds model to the indirect costs categorised into five groups (zero costs comprised group 1 , and the remainder were assigned to quartiles). None of the covariables used emerged as significant factors, but a diagnosis of RA was associated with higher indirect costs (table 5).

Table 1 Patient demographics and selected disease characteristics

\begin{tabular}{|c|c|c|c|c|}
\hline & $\begin{array}{l}\text { RA } \\
(n=253)\end{array}$ & $\begin{array}{l}\mathrm{OA} \text { and } \mathrm{HBP} \\
(\mathrm{n}=191)\end{array}$ & $\begin{array}{l}\text { OA } \\
(n=140)\end{array}$ & $\begin{array}{l}\text { Hypertension } \\
(n=142)\end{array}$ \\
\hline Age (years), mean (SD) & $57.1(13.3)$ & $71.7(8.1)$ & $69.7(8.1)$ & $68.2(8.5)$ \\
\hline Female, No (\%) & $202(79.8 \%)$ & $143(74.9 \%)$ & $97(69.3 \%)$ & $87(61.3 \%)$ \\
\hline Employed full time, No (\%) & $78(30.8 \%)$ & $15(7.9 \%)$ & $12(8.6 \%)$ & $18(12.7 \%)$ \\
\hline$M D$ global $^{*}$, mean $(S D) \dagger$ & $2.4(0.9)$ & $2.8(0.9)$ & $2.7(0.9)$ & $2.1(0.9)$ \\
\hline HAQ disability index $\ddagger$, mean (SD) & $1.2(0.7)$ & $0.9(0.6)$ & $1.0(0.6)$ & $0.4(0.4)$ \\
\hline Global score, question 1 SF36§, mean (SD) & $3.8(1.2)$ & $3.0(0.9)$ & $2.9(1.0)$ & $2.6(0.9)$ \\
\hline Comorbidities $\%$, mean (SD) & $3.1(2.0)$ & $4.0(2.0)$ & $3.5(2.1)$ & $2.8(1.6)$ \\
\hline
\end{tabular}


Table 2 Use of healthcare resources by patients with RA, OA, and hypertension in a 6 month period

\begin{tabular}{|c|c|c|c|c|c|c|c|c|}
\hline & \multicolumn{2}{|l|}{$\mathrm{RA}(\mathrm{n}=253)$} & \multicolumn{2}{|c|}{$O A$ and $\operatorname{HBP}(n=191)$} & \multicolumn{2}{|c|}{$O A(n=140)$} & \multicolumn{2}{|c|}{$\operatorname{HBP}(n=142)$} \\
\hline & No (\%) & Mean (range) & No $(\%)$ & Mean (range) & No $(\%)$ & Mean (range) & No $(\%)$ & Mean (range) \\
\hline At least one visit to a health professional & $253(100)$ & & $191(100)$ & & $140(100)$ & & $142(100)$ & \\
\hline Family physician visits & 215 & $4.8(1-33)$ & 191 & $4.4(1-22)$ & 140 & $4.2(1-24)$ & 142 & $4.3(1-15)$ \\
\hline Non-surgical specialist visits & 253 & $4.2(1-35)$ & 67 & $2.6(1-13)$ & 60 & $2.4(1-23)$ & 40 & $2.1(1-9)$ \\
\hline Surgical specialists & 87 & $2.0(1-10)$ & 55 & $1.6(1-7)$ & 42 & $1.8(1-12)$ & 32 & $1.5(1-4)$ \\
\hline Allied health professionals & 97 & $9.4(1-60)$ & 66 & $9.5(1-40)$ & 55 & $8.6(1-36)$ & 35 & $9.3(1-48)$ \\
\hline Dentists & 115 & $1.8(1-9)$ & 34 & $1.6(1-4)$ & 33 & $1.6(1-6)$ & 40 & $1.3(1-3)$ \\
\hline At least one test or investigation & $239(94.5)$ & & $147(77.0)$ & & 116182.9 & & $104(73.2)$ & \\
\hline$x$ Ray & 117 & $2.3(1-12)$ & 76 & $1.4(1-5)$ & 68 & $1.5(1-4)$ & 36 & $1.5(1-13)$ \\
\hline $\mathrm{CT}$ or MRI & 7 & $1(\mathrm{~N} / \mathrm{A})$ & 8 & $1.1(1-2)$ & 8 & $1.3(1-2)$ & 6 & $1.2(1-2)$ \\
\hline Ultrasound & 40 & $1.2(1-2)$ & 21 & $1.2(1-3)$ & 11 & $1.2(1-2)$ & 15 & $1.1(1-2)$ \\
\hline Electrodiagnostic tests (ECG, etc) & 17 & $1.2(1-3)$ & 15 & $1.2(1-3)$ & 13 & $1.2(1-2)$ & 15 & $1.2(1-3)$ \\
\hline Laboratory tests & 228 & $5.3(1-27)$ & 98 & $2.0(1-26)$ & 84 & $1.8(1-12)$ & 79 & $1.9(1-7)$ \\
\hline Bone density & 23 & $1.0(1-2)$ & 15 & $1.0(1-1)$ & 10 & $1.1(1-2)$ & 6 & $1.0(1-1)$ \\
\hline Other tests or investigations & 26 & $2.1(1-25)$ & 17 & $1.2(1-4)$ & 9 & $1(1-1)$ & 5 & $1.2(1-3)$ \\
\hline Patients hospitalised & $9(3.6)$ & & $9(4.7)$ & & $7(5.0)$ & & $5(3.5)$ & \\
\hline Took drugs & $253(100)$ & $9.0(2-28)$ & $191(100)$ & $7.5(1-18)$ & $140(100)$ & ) 6.7 (1-17) & $142(100)$ & $6.3(1-16)$ \\
\hline Arthritis drugs & 253 & $3.6(1-7)$ & 182 & $1.7(1-4)$ & 131 & $1.8(1-4)$ & 116 & $1.4(1-5)$ \\
\hline Antihypertensive drugs & 72 & $1.6(1-4)$ & 182 & $1.9(1-5)$ & 38 & $1.6(1-3)$ & 141 & $1.9(1-5)$ \\
\hline Gastroprotective drugs & 97 & $1.1(1-3)$ & 61 & $1.1(1-2)$ & 45 & $1.1(1-2)$ & 23 & $1.2(1-3)$ \\
\hline Complementary medicine products & 227 & $3.0(1-12)$ & 159 & $2.6(1-7)$ & 117 & $2.9(1-10)$ & 106 & $2.6(1-12)$ \\
\hline Other drugs & 198 & $2.5(1-13)$ & 157 & $2.8(1-10)$ & 116 & $3.0(1-9)$ & 109 & $2.5(1-7)$ \\
\hline Community services used & $27(10.7)$ & $6.0(1-30)$ & $23(12.0)$ & $4.9(1-15)$ & $16(11.4)$ & $6.0(2-23)$ & $2(1.4)$ & $7.0(2-12)$ \\
\hline Adaptive aids or devices purchased & $50(19.8)$ & $1.9(1-7)$ & $13(6.8)$ & $1.1(1-2)$ & $11(7.9)$ & $1.1(1-2)$ & $1(0.7)$ & $1(\mathrm{~N} / \mathrm{A})$ \\
\hline Unable to do chores (h) & $135(53.4)$ & $207.5(2-1186)$ & $58(30.4)$ & $124.1(3-800)$ & $43(30.7)$ & $243(6-1440)$ & $18(12.7)$ & $172(20-540)$ \\
\hline Needed paid help & $68(26.9)$ & $\mathrm{N} / \mathrm{A}$ & $30(15.7)$ & N/A & $11(7.9)$ & $\mathrm{N} / \mathrm{A}$ & $10(7.0)$ & N/A \\
\hline Needed unpaid help (h) & $149(58.9)$ & $202(2-1638)$ & $31(16.2)$ & $112.2(4-444)$ & $24(17.1)$ & $\begin{array}{l}162.7(12- \\
626)\end{array}$ & 18 (12.7) & $134.0(23-728)$ \\
\hline Patient time off work (h) & $42(16.6)$ & $136.9(6-1208)$ & $1(0.5)$ & 160 (N/A) & $5(3.6)$ & $77.2(8-128)$ & $6(4.2)$ & $272.1(24-760)$ \\
\hline Caregiver time off work (h) & $16(6.3)$ & $46.8(3-336)$ & $1(0.5)$ & 2 (N/A) & $1(0.7)$ & $18(\mathrm{~N} / \mathrm{A})$ & $0(0.0)$ & $8.0(8.0-8.0)$ \\
\hline
\end{tabular}

\section{DISCUSSION}

This was a detailed, patient based COI study in patients with RA and OA in Canada, and one of only a few to attempt a comparison. ${ }^{21}$ Costs of disease were estimated in patients with RA, OA, or HBP recruited consecutively from the offices of family physicians and rheumatologists in Ontario. Estimated total annual costs were approximately: RA \$9300; OA with HBP \$4900; OA alone \$5700; and HBP alone, US\$3900. The findings confirm that patients with RA face higher costs than do those with OA or HBP, while no significant differences in disease costs were found between OA alone or HBP alone. The higher costs associated with RA were accounted for by both higher time and productivity costs and by higher expenditures on tests and visits to specialists. Additionally, the number of comorbidities had a similarly strong association with disease costs for all diagnoses, cancelling out potential effects of age or sex.

Table 3 Cost of illness estimates for 6 months

\begin{tabular}{|c|c|c|c|c|c|c|c|c|}
\hline & \multicolumn{2}{|c|}{$\begin{array}{l}\text { RA } \\
(n=253)\end{array}$} & \multicolumn{2}{|c|}{$\begin{array}{l}\text { OA and HBP } \\
(n=191)\end{array}$} & \multicolumn{2}{|c|}{$\begin{array}{l}\text { OA } \\
(n=140)\end{array}$} & \multicolumn{2}{|c|}{$\begin{array}{l}\text { HBP } \\
(n=142)\end{array}$} \\
\hline & $\$$ & $\%$ & $\$$ & $\%$ & $\overline{\$}$ & $\%$ & $\$$ & $\%$ \\
\hline Total costs & 4674 & & 2456 & & 2856 & & 1963 & \\
\hline Direct costs: total & 2575 & 55.1 & 2024 & 82.4 & 1976 & 69.2 & 1536 & 78.3 \\
\hline Drugs: total & 1237 & & 974 & & 768 & & 786 & \\
\hline Arthritis drugs & 769 & 62.2 & 143 & 14.7 & 163 & 21.2 & 59 & 7.5 \\
\hline Antihypertensive drugs & 52 & 4.2 & 304 & 31.2 & 60 & 7.8 & 283 & 36.0 \\
\hline Gastroprotective drugs & 110 & 8.9 & 96 & 9.9 & 88 & 11.5 & 50 & 6.4 \\
\hline Complementary medicine products & 66 & 5.3 & 47 & 4.9 & 51 & 6.7 & 32 & 4.1 \\
\hline Other prescription drugs & 240 & 19.4 & 383 & 39.4 & 406 & 52.9 & 361 & 46.0 \\
\hline Health professionals: total & 554 & & 339 & & 384 & & 316 & \\
\hline Family doctors & 71 & 12.8 & 113 & 33.3 & 110 & 28.6 & 115 & 36.4 \\
\hline Non-surgeon specialists & 146 & 26.3 & 58 & 17.0 & 69 & 17.9 & 50 & 15.9 \\
\hline Surgeon specialists & 55 & 9.9 & 31 & 9.1 & 27 & 6.9 & 24 & 7.6 \\
\hline Dentists/dental surgeons & 227 & 40.9 & 82 & 24.1 & 109 & 28.3 & 83 & 26.3 \\
\hline Allied health professionals & 56 & 10.1 & 56 & 16.5 & 70 & 18.2 & 44 & 13.8 \\
\hline Separately ordered tests: total & 278 & & 110 & & 119 & & 100 & \\
\hline Hospitalisations: total & 264 & & 393 & & 439 & & 313 & \\
\hline Inpatient hospitalisation costs & 153 & 57.8 & 243 & 61.9 & 300 & 68.4 & 237 & 75.8 \\
\hline Outpatient visit costs & 86 & 32.5 & 64 & 16.2 & 60 & 13.7 & 27 & 8.8 \\
\hline Additional OHIP billings & 25 & 9.6 & 86 & 21.9 & 79 & 18.0 & 48 & 15.4 \\
\hline Community services & 186 & - & 203 & - & 219 & - & 19 & - \\
\hline Aids and devices & 57 & - & 6 & - & 47 & - & 3 & - \\
\hline Indirect costs: total & 2098 & 44.9 & 432 & 17.6 & 880 & 30.8 & 427 & 21.7 \\
\hline Lost time doing chores incl. paid help & 1729 & 82.4 & 418 & 96.8 & 845 & 96.0 & 262 & 61.4 \\
\hline Time lost from work & 326 & 15.5 & 14 & 3.2 & 33 & 3.8 & 164 & 38.3 \\
\hline Support person time lost from work & 44 & 2.1 & 0 & 0.0 & 2 & 0.2 & 1 & 0.3 \\
\hline
\end{tabular}


Table 4 Cost estimates for the three categorical covariables used in the statistical models

\begin{tabular}{|c|c|c|c|c|c|c|c|c|}
\hline & \multicolumn{2}{|c|}{ RA ( $n=253$ ) } & \multicolumn{2}{|c|}{ OA and HBP $(n=191)$} & \multicolumn{2}{|c|}{ OA $(n=140)$} & \multicolumn{2}{|c|}{ HBP $(n=142)$} \\
\hline & $\begin{array}{l}\text { Total } \\
\text { costs (\$) }\end{array}$ & No (\%) & $\begin{array}{l}\text { Total } \\
\text { costs (\$) }\end{array}$ & No (\%) & $\begin{array}{l}\text { Total } \\
\text { costs (\$) }\end{array}$ & No (\%) & $\begin{array}{l}\text { Total } \\
\text { costs (\$) }\end{array}$ & No (\%) \\
\hline \multicolumn{9}{|l|}{ Number of comorbidities } \\
\hline 0 & 3861 & $120(47.4)$ & 1640 & $87(15.1)$ & 2038 & $51(36.4)$ & 1239 & $83(58.5)$ \\
\hline 1 & 3842 & $49(19.4)$ & 2964 & $41(27.2)$ & 1551 & $30(21.4)$ & 1807 & $31(21.8)$ \\
\hline 2 & 6317 & 35 (13.8) & 2186 & $28(20.1)$ & 4008 & $30(21.4)$ & 2919 & $15(10.6)$ \\
\hline$\geqslant 3$ & 6323 & 49 (19.4) & 4102 & $35(37.7)$ & 4455 & $29(20.7)$ & 5855 & $13(9.2)$ \\
\hline \multicolumn{9}{|l|}{ Education } \\
\hline Less than high school & 4435 & $71(28.1)$ & 2572 & $71(35.1)$ & 3060 & $45(32.1)$ & 1559 & $46(32.4)$ \\
\hline High school & 4413 & $68(26.9)$ & 2481 & $66(33.9)$ & 3244 & $45(32.1)$ & 2135 & $57(40.1)$ \\
\hline College or university & 4979 & $114(45.1)$ & 2272 & $54(31.0)$ & 2325 & $50(35.7)$ & 2190 & 39 (27.5) \\
\hline \multicolumn{9}{|l|}{ Sex } \\
\hline Male & 4174 & $51(20.2)$ & 1907 & 48 (41.9) & 3072 & $42(30.0)$ & 2000 & 55 (38.7) \\
\hline Female & 4800 & $202(79.8)$ & 2640 & $143(58.1)$ & 2764 & $98(70.0)$ & 1940 & 87 (61.3) \\
\hline
\end{tabular}

In this study units of health related use of resources and of time and productivity losses were collected in a very detailed questionnaire. Most cost assessment instruments used in rheumatological reports so far have had a limited coverage of all possible cost domains. ${ }^{22}$ Furthermore, we used open ended descriptions for most units, including their intensity and their relationship to a specific health condition. Consequently, very little information may have been lost, a problem that hampers many studies, with increasing levels of aggregation of unit descriptions owing to a lack of detailed reporting. This comprehensive accounting of the use of healthcare resources strengthens the validity of the comparisons, even though patient based reporting may still lead to underestimation of the use of healthcare resources and, consequently, possibly larger differences in healthcare costs among the four diagnostic groups.

As with many COI studies, patients may not be truly representative, because participating patients do not represent those with a similar condition but who do not seek the advice of a family physician or a rheumatologist. These may be people who visit other healthcare providers (different specialists or alternative practitioners), and those who are well enough not to need professional help. However, we would expect the healthcare use of those not represented to be low, and inclusion of their data would reduce the projected total national costs. At the other end of the scale, the absence of patients in the care of an orthopaedic surgeon would be expected to raise the estimate. The cost of joint surgery undergone by four patients with OA during the present survey period was captured, but the total medical expenditure incurred may have been underestimated to some degree.

There is concern that the economic burden of arthritic conditions, primarily OA, will increase, as the "baby boomer" generation gets older. It has been suggested that the costs of arthritic disorders may potentially exceed those of higher profile disorders, such as cardiovascular disease..$^{23}$ The present study provides new information to reassess the importance of disease costs that are attributable to arthritic disorders. Gabriel et al, in a similar study, calculated the direct and indirect costs of OA in a prevalence based cohort of patients in Olmsted County, Minnesota, and compared them with the total costs of illness among non-arthritic controls. ${ }^{21}$ Patients with OA incurred significantly $(\mathrm{p}<0.0001)$ higher direct medical costs (\$2044) than non-arthritic controls (\$1592). In addition, medical costs were $28 \%$ higher among patients with OA (a similar figure to the present finding of $30 \%$ ). However, in their statistical comparison, Gabriel and colleagues adjusted only for age and sex, both of which were found to be nonsignificant contributors in the present study. Indeed, adjustment of the present data for age and sex alone would have resulted in statistically significant differences between OA and HBP. The fact that such differences only became non-significant when adjustment was made for comorbidities and/or global health status confirms that disease costs increase as patients get sicker, potentially not because of their arthritis.

The total costs associated with OA or RA are often estimated to be in the double digit billions of dollars and,

Table 5 Results of regression analyses run separately for total, direct, and indirect costs

\begin{tabular}{|c|c|c|c|c|c|c|c|}
\hline $\begin{array}{l}\text { Dependent } \\
\text { variable* }\end{array}$ & Adj. R2 & Comparisons & B (SE) & $\mathbf{p}$ & Explanatory variables & B (SE) & $\mathbf{p}$ \\
\hline Total costs & 0.31 & $\begin{array}{l}\text { RA } v \text { HBP } \\
\text { OA and HBP } v \text { HBP } \\
\text { OA } v \text { HBP }\end{array}$ & $\begin{array}{l}1.020(0.096) \\
0.249(0.095) \\
0.132(0.102)\end{array}$ & $\begin{array}{l}<0.0001 \\
0.009 \\
0.196\end{array}$ & $\begin{array}{l}\text { Education (3 levels) } \\
\text { Comorbidities (0-23) } \\
\text { Sex } \\
\text { Age (years) }\end{array}$ & $\begin{array}{l}0.022(0.039) \\
0.302(0.028) \\
-0.029(0.072) \\
0.002(0.003)\end{array}$ & $\begin{array}{l}0.577 \\
<0.0001 \\
0.685 \\
0.437\end{array}$ \\
\hline Direct costs & 0.24 & $\begin{array}{l}\text { RA } v \text { HBP } \\
\text { OA and HBP } v \text { HBP } \\
\text { OA } v \text { HBP }\end{array}$ & $\begin{array}{l}0.702(0.085) \\
0.217(0.084) \\
0.050(0.090)\end{array}$ & $\begin{array}{l}<0.0001 \\
0.010 \\
0.580\end{array}$ & $\begin{array}{l}\text { Education } \\
\text { Comorbidities (0-23) } \\
\text { Sex } \\
\text { Age (years) }\end{array}$ & $\begin{array}{l}0.014(0.035) \\
0.276(0.025) \\
0.095(0.064) \\
0.006(0.003)\end{array}$ & $\begin{array}{l}0.552 \\
<0.0001 \\
0.139 \\
0.033\end{array}$ \\
\hline Indirect costs $†$ & 0.14 & $\begin{array}{l}\text { RA } v \text { HBP } \\
\text { OA and HBP } v \text { HBP } \\
\text { OA } v \text { HBP }\end{array}$ & $\begin{array}{l}0.396(0.118) \\
-0.189(0.261) \\
0.343(0.276) \\
\text { OR }(95 \% \mathrm{Cl})\end{array}$ & $\begin{array}{l}0.118 \\
0.468 \\
0.215\end{array}$ & $\begin{array}{l}\text { Education } \\
\text { Comorbidities (0-24) } \\
\text { Sex } \\
\text { Age (years) }\end{array}$ & $\begin{array}{l}0.029(0.080) \\
0.027(0.032) \\
-0.230(0.177) \\
-0.008(0.006) \\
\text { OR }(95 \% \mathrm{Cl})\end{array}$ & $\begin{array}{l}0.716 \\
0.399 \\
0.194 \\
0.128\end{array}$ \\
\hline Indirect costs $\ddagger$ & N/A & $\begin{array}{l}\text { RA } v \text { HBP } \\
\text { OA\&HBP } v \text { HBP } \\
\text { OA } v \text { HBP }\end{array}$ & $\begin{array}{l}1.71(0.82 \text { to } 3.55) \\
0.70(0.33 \text { to } 1.50) \\
1.53(0.68 \text { to } 3.40)\end{array}$ & $\begin{array}{l}0.040 \\
0.010 \\
0.200\end{array}$ & $\begin{array}{l}\text { Education } \\
\text { Comorbidities (0-24) } \\
\text { Sex } \\
\text { Age (years) }\end{array}$ & $\begin{array}{l}0.99(0.79 \text { to } 1.26) \\
1.07(0.98 \text { to } 1.18) \\
0.81(0.48 \text { to } 1.35) \\
0.99(0.97 \text { to } 1.01)\end{array}$ & $\begin{array}{l}0.961 \\
0.133 \\
0.415 \\
0.283\end{array}$ \\
\hline
\end{tabular}

*Dependent variable: log (costs per patient ); †log (non-zero indirect costs); łproportional odds. 
in Canada, were claimed to be "in the neighbourhood of \$C23 billion". However, the total national cost of OA cannot be accurately assessed without reliable estimates of the prevalence of the disease. Data the from the US National Health Interview Survey published by the Centres for Disease Control and Prevention showed that in 1997 the prevalence of arthritic conditions (as determined by specific ICD codes, and with at least some activity limitation) was $2.9 \pm 0.3 \% .^{1}$ If it is assumed that RA limits activity to some extent in every case and has a prevalence of $0.7 \%,{ }^{24}$ and further assumed that the remaining patients all have OA, the prevalence of OA with some form of activity limitation is $2.2 \%$. Extrapolation of these numbers to the Canadian population (31 281092 in the year 2000) and using the cost data reported here, shows that the total cost of RA is of the order of \$C2.01 billion, and that of OA approximately $\$ \mathrm{C} 3.26$ billion. The combined figure of $\$$ C5.27 billion is clearly lower than the \$C23 billion mentioned above, and would account for approximately $0.7 \%$ of the estimated Canadian GDP for the year 2000. Combined direct medical costs would be around \$C3.2 billion, or $0.4 \%$ of the GDP for 2000_far less than most published estimates. This total amount might be at the low end of currently published estimates, owing to a possible underrepresentation of patients with surgery, given the sampling frame of this study. Extrapolation of the cost estimates found in this study to the entire population, however, may provide a more realistic picture of the economic burden of arthritic disorders in Canada, given the frequent overestimation of costs in COI studies. ${ }^{4}$

The relationship between direct medical costs and indirect costs (due to productivity losses or time contributed by care givers) is highly dependent on the estimation methods used. Clarke and associates found that indirect costs were only $34 \%$ of direct costs in RA, ${ }^{25}$ whereas the present data indicate that they are $20 \%$ higher. Kobelt and associates estimated indirect costs to be, on average, 3.2 -fold greater than direct costs. ${ }^{26}$ Estimation of indirect costs is controversial, and current methods give insufficient weight to the potential economic gains that could be achieved by curing diseases that mainly affect women..$^{27}$ However, counting these potentially achievable improvements in productivity as "losses" to society is seldom acceptable to economists - which accounts for the widespread recommendation that indirect costs be excluded from economic evaluations. ${ }^{28}$ An alternative method, the friction cost approach, only includes productivity costs during the period that is needed to restore the initial production level. ${ }^{29}$ Indirect costs measured in this study would potentially overestimate by up to $80 \%$ the indirect costs incurred by society, compared with the friction cost approach.

In conclusion, this prospective evaluation of disease related costs among patients with RA, OA, or HBP showed that expenditure attributable to RA exceeds that related to OA and HBP, while differences between patients with a diagnosis of OA without HBP and a diagnosis of HBP were nonsignificant. The influence of comorbidities on differences in total costs between diseases is significant and needs to be accounted for in future COI studies.

\section{ACKNOWLEDGEMENTS}

This study was supported by an unrestricted grant to the University Health Network Research Institute from Merck Frosst Canada Inc. The terms of the contract stipulate that the authors retain the right to absolute control of the methods, conclusions, and means of publication of the study.

\section{Authors' affiliations}

A Maetzel, L C Li, J Pencharz, C Bombardier, Division of Clinical Decision Making and Health Care Research, University Health Network Research Institute, Toronto, Ontario, Canada
A Maetzel, Department of Health Policy, Management and Evaluation, University of Toronto, Ontario, Canada

L C Li, The Arthritis Society, Ontario Division, Toronto, Ontario, Canada G Tomlinson, C Bombardier, Department of Medicine, University of

Toronto, Ontario, Canada

G Tomlinson, Department of Public Health Sciences, University of

Toronto, Ontario, Canada

C Bombardier, Mt Sinai Hospital, Toronto, Ontario, Canada

\section{REFERENCES}

1 Centers for Disease Control and Prevention (CDC). Prevalence of arthritisUnited States, 1997. MMWR - Morbidity \& Mortality Weekly Report 2001;50:334-6.

2 Centers for Disease Control and Prevention. Arthritis prevalence and activity limitations-United States, 1990. JAMA 1994;272:346-7.

3 Coyte P, Asche C, Croxford R, Chan B. The economic cost of arthritis and rheumatism in Canada. In: Badley EM, Williams JI, eds. Patterns of health care in Ontario: arthritis and related conditions. Toronto: Institute for Clinical Evaluative Sciences, 1998:27-34.

4 Bloom BS, Bruno DJ, Maman DY, Jayadevappa R. Usefulness of US cost-ofillness studies in healthcare decision making. Pharmacoeconomics 2001;19:207-13

5 Koopmanschap MA. Cost-of-illness studies. Useful for health policy? [review]. Pharmacoeconomics 1998;14:143-8.

6 Lawrence RC, Helmick CG, Arnett FC, Deyo RA, Felson DT, Giannini EH, et al. Estimates of the prevalence of arthritis and selected musculoskeletal disorders in the United States [see comments.]. Arthritis Rheum 1998;41:778-99.

7 Guidelines for the management of rheumatoid arthritis. American College of Rheumatology Ad Hoc Committee on Clinical Guidelines. Arthritis Rheum 1996;39:713-22.

8 Stewart AL, Hays RD, Ware JE Jr. The MOS short-form general health survey. Reliability and validity in a patient population. Med Care 1988;26:724-35.

9 Fries JF, Spitz P, Kraines RG, Holman HR. Measurement of patient outcome in arthritis. Arthritis Rheum 1980;23:137-45.

10 Fries JF, Spitz PW, Young DY. The dimensions of health outcomes: the health assessment questionnaire, disability and pain scales. J Rheumatol 1982:9:789-93.

11 Institute of Health Economics. A national list of provincial costs for health care: Canada 1997/8. Edmonton, Alberta: Institute of Health Economics, 2000: 1-125.

12 Statistics Canada. Purchasing power parities/United States dollar per Canadian dollar (SNA Classification, Expenditure-Based). Canada: Statistics (Source: SDDS 1901 STC 13-001), 1999.

13 Ontario Ministry of Health. Schedule of benefits. Physician services under the Health Insurance Act. Toronto: Ontario Ministry of Health, 1998.

14 Canadian Institute for Health Information. CMG directory for use with complexity. Ottawa: Canadian Institute for Health Information, 1994, (ICD-9-CM.)

15 Joint Policy and Planning Committee. Methodology used to calculate adjustment factors model and small hospital funding model (using 1998/ $1999 \mathrm{CIHI}$ and MIS data). RD \#9-7. Toronto, Ontario: Joint Policy and Planning Committee, 2000.

16 Alberta Health and Wellness. Health costing in Alberta - 1999 annual report. Edmonton: Alberta Health and Wellness, 1999.

17 Manning WG, Mullahy J. Estimating log models: to transform or not to transform? J Health Econ 2001;20:461-94.

18 Rutten-van Molken MP, van Doorslaer EK, van Vliet RC. Statistical analysis of cost outcomes in a randomized controlled clinical trial. Health Econ 1994;3:333-45.

19 Duan N. Smearing estimate: a nonparametric retransformation method. J Am Stat Assoc 1983;78:605-10.

20 Chang BH, Pocock S. Analyzing data with clumping at zero. An example demonstration. J Clin Epidemiol 2000;53:1036-43.

21 Gabriel SE, Crowson CS, O'Fallon WM. Costs of osteoarthritis: estimates from a geographically defined population. J Rheumatol Suppl 1995;43:23-5.

22 Ruof J, Merkesdal S, Huelsemann JL, Schoeffski O, Maetzel A, Mau W, et al. Cost assessment instrument in rheumatology: evaluation of applied instrument characteristics [review]. J Rheumatol 2001;28:662-5.

23 Fautrel B, Guillemin F. Cost of illness studies in rheumatic diseases. Curr Opin Rheumatol 2002;14:121-6.

24 Symmons DP, Silman AJ. The epidemiology of rheumatoid arthritis. In: Wolfe F, Pincus T, eds. Rheumatoid arthritis. Pathogenesis, assessment, outcome and treatment. New York, Basel, Hong Kong: Marcel Dekker Inc, 1994:131-49.

25 Clarke AE, Zowall H, Levinton C, Assimakopoulos H, Sibley JT, Haga M, et al. Direct and indirect medical costs incurred by Canadian patients with rheumatoid arthritis: a 12 year study. J Rheumatol 1997;24:1051-60.

26 Kobelt G, Eberhardt K, Jonsson L, Jonsson B. Economic consequences of the progression of rheumatoid arthritis in Sweden. Arthritis Rheum 1999;42:347-56.

27 Clarke AE, Penrod J, St Pierre Y, Petri MA, Manzi S, Isenberg DA, et al. Underestimating the value of women: assessing the indirect costs of women with systemic lupus erythematosus. Tri-Nation Study Group. J Rheumatol 2000;27:2597-604.

28 Gold MR, Siegel JE, Russell LB, Weinstein MC. Cost-effectiveness in health and medicine. New York, Oxford: Oxford University Press, 1996.

29 Koopmanschap MA, van Ineveld BM. Towards a new approach for estimating indirect costs of disease. Soc Sci Med 1992;34:1005-10. 